Cold Spring Harb Perspect Med 4: a014357 (2014)

\title{
An Overview of MYC and Its Interactome
}

\author{
Maralice Conacci-Sorrell, Lisa McFerrin, and Robert N. Eisenman
}

In the original version of this article, one of the text labels in Figure 1 was incorrect: The MYC exons involved in translocation were labeled as being located on Chromosome 18. However, the human MYC gene is on Chromosome 8, not Chromosome 18. The authors apologize for this error. A corrected version of Figure 1 is below. Figure 1 has also been amended in the current PDF and HTML versions of the article.

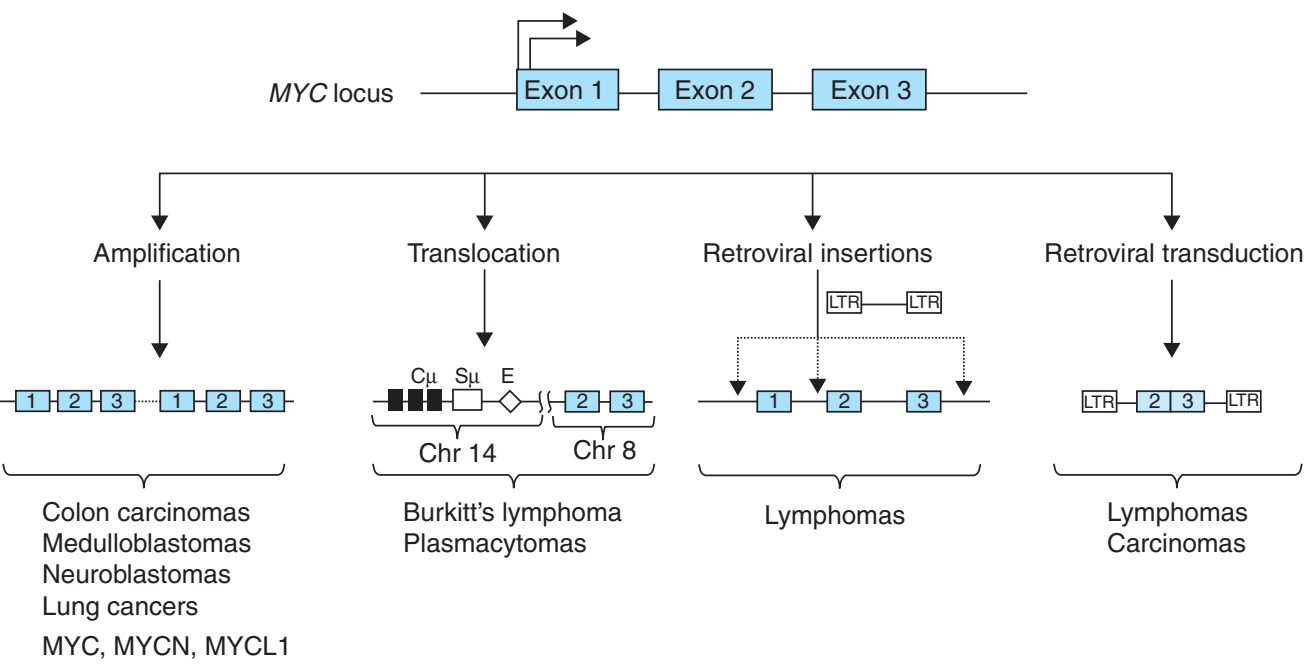

Figure 1. Genetic rearrangements associated with the MYC locus in diverse cancers (partial list). 


\section{$\&_{\mathrm{CSH}}^{\infty} \&$ Cold Spring Harbor $\stackrel{\text { PERSPECTIVES }}{\longrightarrow \infty_{\infty}}$ Perspectives in Medicine}

\section{An Overview of MYC and Its Interactome}

Maralice Conacci-Sorrell, Lisa McFerrin and Robert N. Eisenman

Cold Spring Harb Perspect Med 2014; doi: 10.1101/cshperspect.a023325

Subject Collection

For additional articles in this collection, see http://perspectivesinmedicine.cshlp.org/cgi/collection/ 